\title{
Safety of total gastrectomy without nasogastric and nutritional intubation
}

\author{
HONG-WEI ZHANG，LI SUN，XUE-WEN YANG，FAN FENG and GUO-CAI LI \\ First Department of Digestive Surgery, Xijing Hospital of Digestive Diseases, \\ Fourth Military Medical University, Xi'an, Shaanxi 710032, P.R. China
}

Received July 22, 2016; Accepted April 3, 2017

DOI: $10.3892 / \mathrm{mco} .2017 .1331$

\begin{abstract}
The aim of the present study was to evaluate the safety of gastrectomy without nasogastric and nutritional intubations. Between January 2010 and August 2015, 74 patients with gastric cancer received total gastric resection and esophagogastric anastomosis without nasogastric and nutritional intubations at the First Department of Digestive Surgery of the XiJing Hospital of Digestive Diseases (Xi'an, China), of whom 42 were also received earlier oral feeding within $48 \mathrm{~h}$. The data were retrospectively analyzed. An additional 301 cases who underwent traditional postoperative intubation were used for comparison. In patients without intubation compared with those managed traditionally with intubation, the mean operative time was decreased (190.97 \pm 38.18 vs. $216.12 \pm 59.52 \mathrm{~min}$, respectively; $\mathrm{P}=0.026)$. In addition, the postoperative activity was resumed earlier (1.16 \pm 0.47 vs. $1.36 \pm 0.84$ days, respectively; $\mathrm{P}=0.009)$, oral food intake was started earlier (4.28 \pm 1.79 vs. $5.71 \pm 2.66$ days, respectively; $\mathrm{P}=0.009)$, the incidence of fever was lower $(12.16$ vs. $29.23 \%$, respectively; $\mathrm{P}=0.003$ ), and the incidence of total complications was not statistically significantly different between the two groups (9.41 vs. 6.31\%, respectively; $\mathrm{P}=0.317$ ). There were no significant differences regarding complications of the anastomotic port (1.37 vs. $1.69 \%$, respectively; $\mathrm{P}=0.849$ ). Compared with traditional postoperative management, earlier oral feeding did not increase the incidence of complications (7.21 vs. $4.76 \%$, respectively; $\mathrm{P}=0.557$ ). Our results suggest that total gastric resection without nasogastric and nutritional intubation is a safe and feasible option for patients undergoing total gastrectomy.
\end{abstract}

Correspondence to: Dr Guo-Cai Li, First Department of Digestive Surgery, Xijing Hospital of Digestive Diseases, Fourth Military Medical University, 15 West Changle Road, Xi'an, Shaanxi 710032, P.R. China

E-mail: mrlgc@163.com

Key words: nasogastric tube, nutritional tube, fast-track surgery, complications

\section{Introduction}

Nasogastric and nutritional tubes are routinely used for decompression and nutrient supply following total gastrectomy in patients with gastric cancer. However, the traditional algorithm was recently challenged by an increasing number of studies.

Enhanced Recovery After Surgery (ERAS), also referred to as 'fast-track' (FT) perioperative care, initiated by Bardram et al in 1995 (1), represents a fundamental shift in perioperative care (2-4). ERAS consists of multidisciplinary approaches, including no bowel preparation $(5,6)$, free intake of fluid (7) and no routine use of nasogastric tubes or drains. Compared with traditional management, ERAS contributes to shortening the time to passing of flatus and reducing hospitalization costs (3), without an increase in postoperative complications $(8,9)$.

Apart from nausea, pharyngeal discomfort and surgical stress, it has been reported that fever and pneumonia also occur more frequently in patients with nasogastric intubation compared with those without intubation $(4,10)$, whereas the incidence of gastro-esophageal reflux is increased and bowel function is restored later in cases with nasogastric intubation (4,11-13). These data provide strong evidence that routine nasogastric intubation should be avoided. However, although avoiding gastric intubation is often reported in recent studies on abdominal surgery, studies on avoiding nasogastric and nutritional intubation in total gastric resection surgery are rare and evidence is scarce.

According to ERAS, the majority of the patients may drink and eat normal hospital food immediately following recovery from anaesthesia (14-16). It has reported that early oral food intake is safe and feasible following upper gastrointestinal and hepatopancreaticobiliary surgery (17), and it may contribute to reducing the rate of infection and anastomotic dehiscence $(18,19)$. However, the safety of early oral intake following total gastric resection and esophagogastric anastomosis remains unclear.

The aim of the present study was to investigate the safety of total gastric resection without nasogastric and nutritional intubation and with earlier oral feeding.

\section{Patients and methods}

Patients. Between January 2010 and August 2015, 791 consecutive patients with gastric cancer underwent gastrectomy by the 
same surgical team at the First Department of Digestive Surgery of XiJing Hospital, Fourth Military Medical University (Xi'an, China). For this retrospective cohort study, all patient data were evaluated by two researchers and the patient inclusion criteria were as follows: i) Adult patients (age $>18$ years); ii) patients with gastric cancer who underwent total gastric resection and esophagojejunal anastomosis; all surgeries performed under general anaesthesia, and spleen-preserving D2 lymphadenectomy was performed. An end-to-side Roux-Y anastomosis was created with a $26-\mathrm{mm}$ diameter circular stapler.

This study was approved by the Ethics Committee of the Fourth Military Medical University. All patients received verbal and written information regarding the study and provided informed consent prior to surgery.

Demographic and preoperative data. Demographic data, including sex, age, smoking status, alcohol consumption and disease history were collected. Preoperative data, including TNM clinical and pathological staging classification, routine hematological and biochemical tests and X-rays were collected to enable subsequent analysis of the comparability of the groups.

Postoperative caring. The patients were divided into two groups: The traditional group underwent insertion of nasogastric and nutritional tubes perioperatively, and the nasogastric tube was maintained until intestinal recovery, which was identified by the first passage of flatus, and the nutritional tube was maintained until ingestion of normal food was resumed. The FT group did not undergo insertion of a nasogastric or nutritional tube.

Perioperative observations and data collection. The surgical time was calculated from the first skin incision to placement of the last suture. The recovery time of gastrointestinal function, intraoperative blood loss, and the highest postoperative temperature were recorded. The histological subtype and pathological stage were determined using the Union for International Cancer Control and TNM classification for gastric cancer. Blood samples were collected and routine blood test, liver and renal function tests were performed perioperatively. Postoperative complications, including anastomotic complication, wound infection, wound rupture, lung infection, bleeding, reoperation, duodenal leak and intestinal obstruction were observed and evaluated. Anastomotic complication assessment was performed using a water-soluble radiological contrast enema at 6-8 days postoperatively. A clinical leak was defined as the appearance of food material in the abdominal drains, or the development of systemic sepsis associated with local peritoneal signs during the postoperative period. Any extravasation of the contrast medium detected on radiography was considered as a radiological leak.

Statistical analysis. Statistical analysis was performed using SPSS 11.5 software (SPSS Inc., Chicago, IL, USA). Differences in expression rate among groups were analyzed by Pearson's Chi-squared $\left(\chi^{2}\right)$ test. The Fisher's exact test was used to assess the difference of positive rate when the number of total cases was $<40$. All statistical tests were two-sided; a P-value of $<0.05$

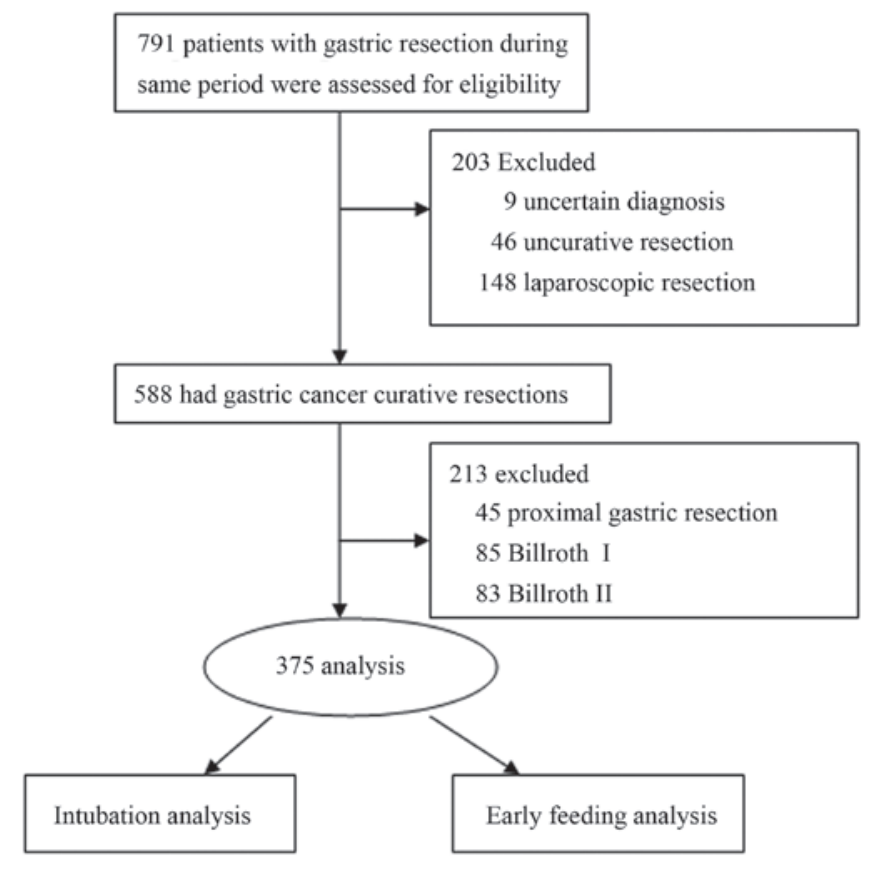

Figure 1. Flow diagraph of patients enrollment.

was considered statistically significant. Hierarchical logistic regression was used to determine the association between tube insertion and complications, and between eating time and complications.

\section{Results}

Characteristics of patients. A total of 375 cases met the inclusion criteria and were analyzed in this cohort study (Fig. 1), of whom 74 cases without gastric and nutritional intubation were classified into the FT group, and the 301 cases with intubations were classified into the traditional group for comparison. The comparison of baseline data between the FT and traditional groups is described in Table I. There were no significant differences between the two groups regarding preoperative variables, such as age, sex, tumor differentiation, pathological stage, histological subtype, TNM stage, laboratory test and basic health status.

Comparison of intraoperative and postoperative data. The mean surgical time in the FT group was significantly shortened compared with the traditional group $(190.97 \pm 38.18$ vs. $216.12 \pm 59.52 \mathrm{~min}$, respectively; $\mathrm{P}=0.026$ ). The activity was resumed earlier ( $1.16 \pm 0.47$ vs. $1.36 \pm 0.84$ days, respectively; $\mathrm{P}=0.009)$ and time to oral intake was also shorter $(4.28 \pm 1.79$ vs. 5.71 \pm 2.66 days, respectively; $\mathrm{P}=0.001)$. Moreover, fewer patients developed a fever in the FT compared with the traditional group (12.16 vs. $29.23 \%$, respectively; $\mathrm{P}=0.003)$. There was no significant difference in the amount of intraoperative blood loss, highest postoperative temperature, time to first flatus and postoperative hospital stay between the two groups (Table II).

Complications. The distribution of complications in all the patients is outlined in Fig. 2. Postoperative complications 
Table I. Patient characteristics.

\begin{tabular}{|c|c|c|c|}
\hline \multirow[b]{2}{*}{ Variables } & \multicolumn{2}{|c|}{ Nutritional tube, $\mathrm{n}$} & \multirow{2}{*}{ P-value } \\
\hline & No & Yes & \\
\hline \multicolumn{4}{|l|}{ Sex } \\
\hline Male & 59 & 245 & \multirow[t]{2}{*}{0.743} \\
\hline Female & 15 & 56 & \\
\hline Age, years $($ mean $\pm S D)$ & $56.32 \pm 11.53$ & $58.33 \pm 10.43$ & 0.075 \\
\hline \multicolumn{4}{|l|}{ Gastric tube } \\
\hline No & 6 & 42 & \multirow[t]{2}{*}{0.178} \\
\hline Yes & 68 & 259 & \\
\hline \multicolumn{4}{|l|}{ Hypertension } \\
\hline No & 67 & 248 & \multirow[t]{2}{*}{0.087} \\
\hline Yes & 7 & 53 & \\
\hline \multicolumn{4}{|l|}{ Heart disease } \\
\hline No & 73 & 290 & \multirow[t]{2}{*}{0.429} \\
\hline Yes & 1 & 11 & \\
\hline \multicolumn{4}{|l|}{ Diabetes } \\
\hline No & 72 & 274 & \multirow[t]{2}{*}{0.106} \\
\hline Yes & 2 & 24 & \\
\hline \multicolumn{4}{|l|}{ Lung disease } \\
\hline No & 73 & 294 & \multirow[t]{2}{*}{0.995} \\
\hline Yes & 1 & 4 & \\
\hline \multicolumn{4}{|l|}{ Laboratory tests (mean $\pm \mathrm{SD}$ ) } \\
\hline WBC count $\left(\times 10^{9} / 1\right)$ & $5.97 \pm 1.91$ & $6.08 \pm 1.93$ & 0.664 \\
\hline $\mathrm{RBC}$ count $\left(\times 10^{12} / \mathrm{l}\right)$ & $4.42 \pm 0.60$ & $4.35 \pm 0.54$ & 0.375 \\
\hline Hb level $(\mathrm{g} / \mathrm{l})$ & $132.16 \pm 26.09$ & $127.86 \pm 20.89$ & 0.133 \\
\hline $\mathrm{TP}(\mathrm{g} / \mathrm{l})$ & $69.20 \pm 6.09$ & $68.28 \pm 5.18$ & 0.188 \\
\hline \multicolumn{4}{|l|}{ Pathological type } \\
\hline Papillary adenocarcinoma & 0 & 2 & \multirow[t]{6}{*}{0.442} \\
\hline High differentiation & 13 & 44 & \\
\hline Intermediate differentiation & 6 & 45 & \\
\hline Poor differentiation & 40 & 162 & \\
\hline Mucous & 9 & 34 & \\
\hline Others & 5 & 8 & \\
\hline \multicolumn{4}{|l|}{ TNM stage } \\
\hline Tis & 1 & 1 & \multirow[t]{7}{*}{0.884} \\
\hline Ia & 23 & 112 & \\
\hline $\mathrm{Ib}$ & 2 & 9 & \\
\hline II & 5 & 17 & \\
\hline IIIa & 6 & 19 & \\
\hline IIIb & 5 & 17 & \\
\hline IV & 32 & 126 & \\
\hline
\end{tabular}

The Student's t-test was used to analyze statistically significant differences in age and laboratory test results between the non-intubation and intubation groups. SD, standard deviation; RBC, red blood cell; WBC, white blood cell; Hb, hemoglobin; TP, total serum protein. Chi-square test were used to analyze categorical variables.

included lung infection $3.60 \%$, wound infection $0.20 \%$, wound rupture $1.60 \%$, anastomotic leakage $1.90 \%$, bleeding $1.10 \%$, duodenal leak $1.30 \%$, intestinal obstruction $1.60 \%$ and reoperation $1.60 \%$ in all the patients.
The incidence rate of total complications in the FT group was not statistically significantly different from that in the traditional group ( 9.45 vs. $6.31 \%$, respectively; $\mathrm{P}=0.317)$. In addition, there were no differences regarding lung infection, 
Table II. Perioperative observation.

\begin{tabular}{lccr}
\hline & \multicolumn{2}{c}{ Intubation } & P-value \\
\cline { 2 - 3 } Variables & No & Yes & 0.026 \\
\hline Operative time (min) & $190.97 \pm 38.18$ & $216.12 \pm 59.52$ & 0.009 \\
Activity (days) & $1.16 \pm 0.47$ & $1.36 \pm 0.84$ & 0.001 \\
Oral intake (days) & $4.28 \pm 1.79$ & $5.71 \pm 2.66$ & 0.060 \\
Blood loss (ml) & $240.27 \pm 199.32$ & $295.15 \pm 229.70$ & 0.003 \\
Fever (\%) & $9(12.16 \%)$ & $88(29.23 \%)$ & 0.119 \\
Postoperative hospital stay (days) & $9.00 \pm 4.2$ & $9.84 \pm 4.12$ & 0.374 \\
Intestinal function recovery (days) & $4.13 \pm 1.37$ & $4.31 \pm 1.51$ & \\
\hline
\end{tabular}

The Student's t-test and Chi-squared test were used to analyze statistically significant differences between the non-intubation and intubation groups. Values are presented as mean \pm standard deviation.

wound infection, wound rupture, anastomotic leakage, bleeding, duodenal leak, intestinal obstruction and reoperation rate according to the univariate analysis (Table III).

Time to oral intake and complications. The distribution of time to oral intake and time to first flatus of all patients is presented in Fig. 3, ranging from the 1st to the 13th postoperative day. The mean time to the first oral intake time was $5.42 \pm 2.47$ days, while 18 (4.9\%), 24 (6.5\%), 25 (6.8\%) and 300 $(81.7 \%)$ patients were fed on the 1st, 2 nd, 3rd and after the 4 th postoperative day, respectively. The mean time to first flatus of all patients was $4.28 \pm 1.48$ days, while 0 (0.0\%), 15 (4.5\%), 132 $(35.0 \%)$ and $320(60 \%)$ patients passed flatus on the 1st, 2nd, 3 rd and after the 4 th postoperative day.

The traditional standard for resuming oral feeding is after the first flatus or 6 days later after expelling anastomostic leakage by radiological tests. We determined $48 \mathrm{~h}$ as the cut-off for earlier feeding, and found that 17 (23\%) patients were fed earlier in the FT group vs. $25(8.3 \%)$ patients in the traditional group $(\mathrm{P}<0.001)$. It was also observed that earlier feeding did not significantly increase the rate of total complications (7.21 vs. $4.76 \%$, respectively, $\mathrm{P}=0.557$; Table IV).

Safety of non-intubation and earlier feeding evaluated by multivariate analysis. To further assess the risk of postoperative complications, a multivariate analysis was conducted using the logistic regression model, including tumor stage, tumor grade, age, sex, pathological type, underlying disease and surgical bleeding. The analysis demonstrated that non-intubation contributed to a decrease in the total complication rate [odds ratio $(\mathrm{OR})=2.65, \mathrm{P}=0.063]$. Moreover, by logistic regression analysis, earlier feeding did not increase the risk of postoperative complications $(\mathrm{OR}=1.63, \mathrm{P}=0.543)$ (Table V).

\section{Discussion}

The aim of the present study was to investigate a new management in total gastric resection, without insertion of gastric or nutritional tubes. It was demonstrated that this approach is feasible and appears to be as safe as the traditional method. Compared with the traditional method, the FT
Table III. Comparison of complications in gastric resection with and without intubation.

\begin{tabular}{lccc}
\hline & \multicolumn{2}{c}{ Intubation, $\mathrm{n}(\%)$} & \\
\cline { 2 - 3 } Complications & No & Yes & P-value \\
\hline Lung infection & $1(1.35)$ & $8(2.65)$ & 0.511 \\
Wound infection & $1(1.35)$ & 0 & 0.197 \\
Wound rupture & $2(2.70)$ & $4(1.32)$ & 0.338 \\
Reoperation & $1(1.35)$ & $5(1.66)$ & 0.849 \\
Bleeding & 0 & $5(1.66)$ & 0.588 \\
Duodenal leak & 0 & $7(2.32)$ & 0.353 \\
Anastomotic leakage & $1(1.35)$ & $2(0.66)$ & 0.552 \\
Intestinal obstruction & $2(2.70)$ & $4(1.32)$ & 0.338 \\
Total complications & $7(9.45)$ & $19(6.31)$ & 0.317 \\
\hline
\end{tabular}

The Chi-squared test was used to analyze statistically significant differences between the non-intubation and intubation groups.

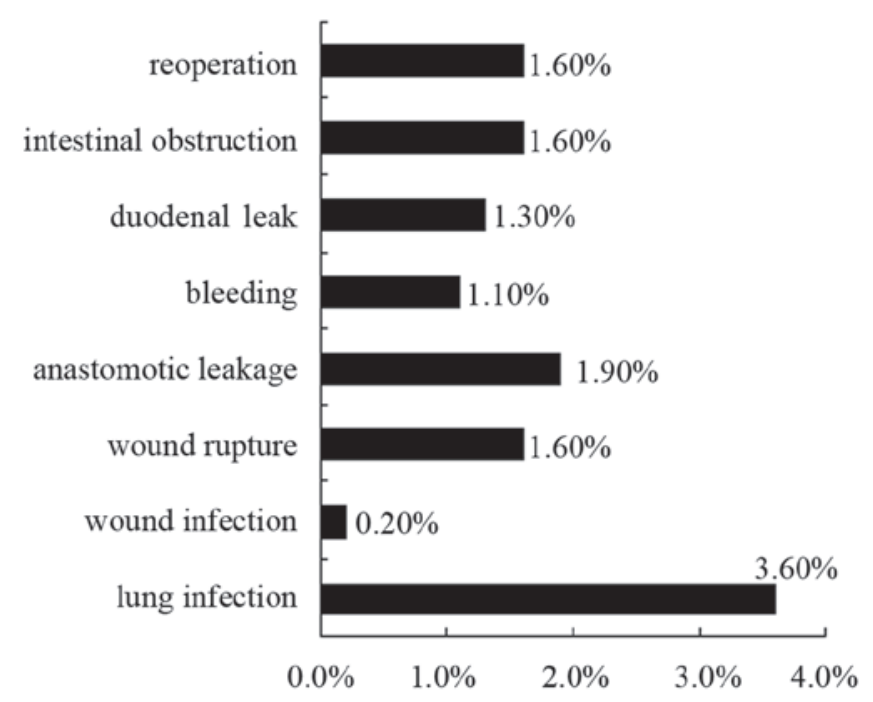

Figure 2. The distribution of total complications in all patients with total gastric resection. 
Table IV. Earlier oral feeding and complication rate.

\begin{tabular}{lccc}
\hline & \multicolumn{2}{c}{ Earlier feeding, n $(\%)$} & \\
\cline { 2 - 3 } Complications & No & Yes & P-value \\
\hline Fever & $86(25.82)$ & $11(26.19)$ & 0.959 \\
Lung infection & $9(2.70)$ & 0 & 0.606 \\
Wound infection & 0 & $1(2.38)$ & 0.112 \\
Wound rupture & $6(1.80)$ & $2(4.76)$ & 0.337 \\
Reoperation & $6(1.80)$ & 0 & 0.381 \\
Bleeding & $5(1.50)$ & 0 & 0.424 \\
Duodenal leak & $7(2.10)$ & 0 & 0.343 \\
Anastomotic leakage & $3(0.90)$ & 0 & 0.537 \\
Intestinal obstruction & $6(1.80)$ & 0 & 0.381 \\
Total complications & $24(7.21)$ & $2(4.76)$ & 0.557
\end{tabular}

The Chi-squared test was used to analyze statistically significant differences between the two groups.

Table V. Association between intubation and morbidity of complications by logistic regression analysis.

\begin{tabular}{lcccc}
\hline \multirow{2}{*}{ Variables } & $\begin{array}{c}\text { Regression } \\
\text { coefficient }\end{array}$ & $\begin{array}{c}\text { Standard } \\
\text { error }\end{array}$ & OR & P-value \\
\hline Intubation & 0.97 & 0.52 & 2.65 & 0.063 \\
Operative time (min) & 0.00 & 0.00 & 1.00 & 0.407 \\
Feeding time (days) & 0.49 & 0.80 & 1.63 & 0.543 \\
Sex & -0.53 & 0.65 & 0.59 & 0.412 \\
Age & 0.05 & 0.02 & 1.05 & 0.025 \\
Basic disease & -0.39 & 0.42 & 0.68 & 0.345 \\
Blood loss (ml) & 0.00 & 0.00 & 1.00 & 0.628 \\
Pathological type & 0.15 & 0.54 & 1.16 & 0.785 \\
Degree of differentiation & 0.39 & 0.25 & 1.48 & 0.123 \\
TNM stage & -0.10 & 0.10 & 0.90 & 0.276 \\
Constant & -8.47 & 2.39 & 0.01 & 0.001 \\
\hline
\end{tabular}

Nutritional and gastric intubation was coded as $0=$ no and $1=y e s ;$ operative time was recorded from the beginning to the end of the operations; feeding time was coded as $0=$ later feeding and $1=$ earlier feeding; Sex was coded as $1=$ male and $2=$ female. Basic disease included hypertension, heart disease, diabetes mellitus, lung disease and was coded as $0=$ no and $1=$ yes. Blood loss was recorded according to the operative records. Pathological type included highly, intermediately and poorly differentiated adenocarcinoma, and was coded as 1, 2 and 3, respectively. The degree of differentiation included high, intermediate and poor differentiation. The TNM stage were classified as Tis, Ia, Ib, II, IIIa, IIIb and IV, and was coded as 17, respectively.

management contributed to reduced rate of fever, promoted intestinal function recovery and decreased the rate of complications.

A previous meta-analysis reported a short interval from surgery to the first passage of flatus and a short length of hospital stay if nasogastric intubation was avoided $(20,21)$.

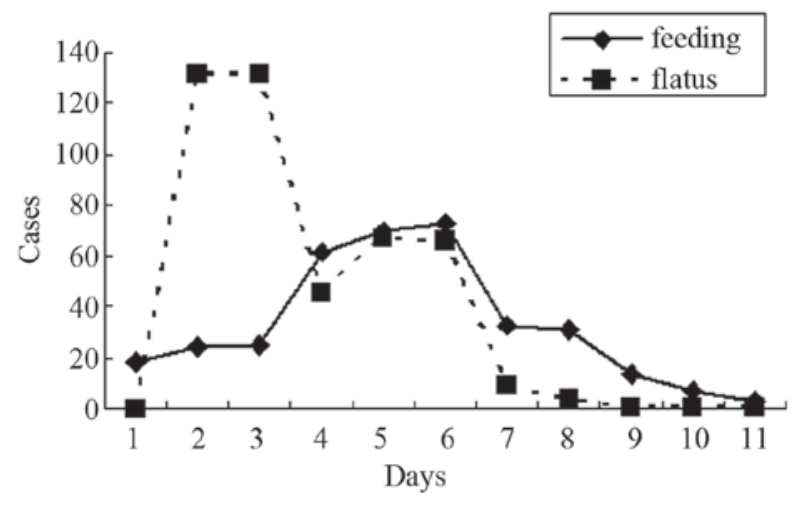

Figure 3. The distribution of the first oral feeding (days) and the first flatus (days) in all patients with total gastric resection.

The incidence of pulmonary complications, wound infection and anastomotic leakage was also not significantly different in colorectal surgery without intubation (22). In accordance with these previous findings, we observed that gastric and nutritional intubation prolonged operative time, increased the incidence of fever, and increased the rate of total complications according to the logistic regression analysis.

The safety of total gastric resection is closely associated with anastomotic healing, which depends on adequate blood supply and good nutritional status of anastomotic tissue (23-25). It is generally accepted that the strength of the anastomosed intestinal wall is largely derived from collagen (26). During the first postoperative days, wound strength is considered to solely depend on the suture-holding capacity of the existing collagen fibrils (27). From $3 \mathrm{~h}$ to 4 days after the operation, the absolute and the relative collagen synthesis steadily increases $(26,28)$, providing evidence that an anastomosis strength increases from the beginning of wound healing, and the risk of anastomotic leakage decreases. The role of intubation in the healing of anastomosis is controversial, as a previous study demonstrated that an indwelling catheter traversing the anastomosis slows down the healing process in that segment (29).

The fast-track approach theory emphasizes that earlier food intake promotes intestinal function recovery $(30,31)$, and earlier food intake from the first postoperative day after duodenopancreatectomy was proven to be safe $(17,32)$. Moreover, it was reported that early post-pyloric feeding offers no advantage over early gastric feeding in terms of overall nutrition received and complications (33), which also reflects the safety of earlier oral intake in upper digestive tract surgery. Our results also suggest that earlier oral intake within $48 \mathrm{~h}$ is safe and feasible in patients undergoing total gastric resection and esophagojejunal anastomosis.

Although gastric and nutritional intubations were suggested to be avoided in our study, this may not apply to all patients. Under certain condition, such as anastomotic complications, duodenal leakage and intestinal obstruction, intubations are required to decompress and supply nutrition and, particularly, intubation contributes to relieving delayed emptying of the upper digestive tract and severe distention $(4,32,34,35)$.

In conclusion, our results suggest that total gastric resection without intubations and earlier feeding is a novel, feasible and 
safe method, which may simplify the surgical procedure and reduce overall complication rate and may applied to selected patients.

\section{Acknowledgements}

The authors would like to thank Dr Guang-Hui Xu,Dr LeiZhang and Dr Lei Cai for their help in the design, analysis and writing of this article.

\section{References}

1. Bardram L, Funch-Jensen P, Jensen P, Crawford ME and Kehlet H: Recovery after laparoscopic colonic surgery with epidural analgesia, and early oral nutrition and mobilisation. Lancet 345: 763-764, 1995.

2. Nygren J, Thacker J, Carli F, Fearon KC, Norderval S, Lobo DN, Ljungqvist O, Soop M and Ramirez J; Enhanced Recovery After Surgery Society: Guidelines for perioperative care in elective rectal/pelvic surgery: Enhanced Recovery After Surgery (ERAS®) Society recommendations. Clin Nutr 31: 801-816, 2012.

3. Gustafsson UO, Scott MJ, Schwenk W, Demartines N, Roulin D, Francis N, McNaught CE, Macfie J, Liberman AS, Soop M, et al: Guidelines for perioperative care in elective colonic surgery: Enhanced Recovery After Surgery (ERAS (®)) Society recommendations. World J Surg 37: 259-284, 2013.

4. Lassen K,Coolsen MM,Slim K, Carli F, de Aguilar-NascimentoJE, Schäfer M, Parks RW, Fearon KC, Lobo DN, Demartines N, et al: Guidelines for perioperative care for pancreaticoduodenectomy: Enhanced Recovery After Surgery (ERAS $($ ) Society recommendations. World J Surg 37: 240-258, 2013.

5. Holte K, Nielsen KG, Madsen JL and Kehlet H: Physiologic effects of bowel preparation. Dis Colon Rectum 47: 1397-1402, 2004.

6. Jung B, Lannerstad O, Påhlman L, Arodell M, Unosson M and Nilsson E: Preoperative mechanical preparation of the colon: The patient's experience. BMC Surg 7: 5, 2007.

7. Ljungqvist $\mathrm{O}$ and Søreide E: Preoperative fasting. Br J Surg 90 400-406, 2003.

8. Li YJ, Huo TT, Xing J, An JZ, Han ZY, Liu XN and Zhao QC: Meta-analysis of efficacy and safety of fast-track surgery in gastrectomy for gastric cancer. World J Surg 38: 3142-3151, 2014.

9. Feng F, Ji G, Li JP, Li XH, Shi H, Zhao ZW, Wu GS, Liu XN and Zhao QC: Fast-track surgery could improve postoperative recovery in radical total gastrectomy patients. World J Gastroenterol 19: 3642-3648, 2013.

10. Cheatham ML, Chapman WC, Key SP and Sawyers JL: A meta-analysis of selective versus routine nasogastric decompression after elective laparotomy. Ann Surg 221: 469-478, 1995.

11. Manning BJ, Winter DC, McGreal G, Kirwan WO and Redmond HP: Nasogastric intubation causes gastroesophageal reflux in patients undergoing elective laparotomy. Surgery 130: 788-791, 2001.

12. Fisher WE, Hodges SE, Cruz G, Artinyan A, Silberfein EJ, Ahern $\mathrm{CH}$, Jo E and Brunicardi FC: Routine nasogastric suction may be unnecessary after a pancreatic resection. HPB (Oxford) 13: 792-796, 2011

13. Roland CL, Mansour JC and Schwarz RE: Routine nasogastric decompression is unnecessary after pancreatic resections. Arch Surg 147: 287-289, 2012.

14. Gustafsson UO, Thorell A, Soop M, Ljungqvist O and Nygren J: Haemoglobin Alc as a predictor of postoperative hyperglycaemia and complications after major colorectal surgery. Br J Surg 96 1358-1364, 2009.

15. Hendry PO, Hausel J, Nygren J, Lassen K, Dejong $\mathrm{CH}$, Ljungqvist $\mathrm{O}$ and Faron KC; Enhanced Recovery After Surgery Study Group: Determinants of outcome after colorectal resection within an enhanced recovery programme. Br J Surg 96: 197-205, 2009.
16. Nygren J, Soop M, Thorell A, Hausel J and Ljungqvist O; ERAS Group: An enhanced-recovery protocol improves outcome after colorectal resection already during the first year: A single-center experience in 168 consecutive patients. Dis Colon Rectum 52: 978-985, 2009.

17. Lassen K, Kjaeve J, Fetveit T, Tran $\varnothing$ G, Sigurdsson HK, Horn A and Revhaug A: Allowing normal food at will after major upper gastrointestinal surgery does not increase morbidity: A randomized multicenter trial. Ann Surg 247: 721-729, 2008.

18. Lewis SJ, Egger M, Sylvester PA and Thomas S: Early enteral feeding versus 'nil by mouth' after gastrointestinal surgery: Systematic review and meta-analysis of controlled trials. BMJ 323: 773-776, 2001.

19. Han-Geurts IJ, Hop WC, Kok NF, Lim A, Brouwer KJ and Jeekel J: Randomized clinical trial of the impact of early enteral feeding on postoperative ileus and recovery. Br J Surg 94: 555-561, 2007.

20. Nelson R, Tse B and Edwards S: Systematic review of prophylactic nasogastric decompression after abdominal operations. $\mathrm{Br}$ J Surg 92: 673-680, 2005.

21. Rao W, Zhang X, Zhang J, Yan R, Hu Z and Wang Q: The role of nasogastric tube in decompression after elective colon and rectum surgery: A meta-analysis. Int J Colorectal Dis 26: 423-429, 2011.

22. Mack LA, Kaklamanos IG, Livingstone AS, Levi JU, Robinson C, Sleeman D, Franceschi D and Bathe OF: Gastric decompression and enteral feeding through a double-lumen gastrojejunostomy tube improves outcomes after pancreaticoduodenectomy. Ann Surg 240: 845-851, 2004.

23. Chung RS: Blood flow in colonic anastomoses. Effect of stapling and suturing. Ann Surg 206: 335-339, 1987.

24. Fawcett A, Shembekar M, Church JS, Vashisht R, Springall RG and Nott DM: Smoking, hypertension and colonic anastomotic healing; A combined clinical and histopathological study. Gut 38: 714-718, 1996.

25. Markar SR, Karthikesalingam A, Vyas S, Hashemi M and Winslet M: Hand-sewn versus stapled oesophago-gastric anastomosis: Systematic review and meta-analysis. J Gastrointest Surg 15: 876-884, 2011.

26. Martens MF and Hendriks T: Postoperative changes in collagen synthesis in intestinal anastomoses of the rat: Differences between small and large bowel. Gut 32: 1482-1487, 1991.

27. Högström H and Haglund U: Postoperative decrease in suture holding capacity in laparotomy wounds and anastomoses. Acta Chir Scand 151: 533-535, 1985

28. de Waard JW, Wobbes T, de Man BM, van der Linden CJ and Hendriks T: Post-operative levamisole may compromise early healing of experimental intestinal anastomoses. Br J Cancer 72: 456-460, 1995

29. Borgstrom S and Lundh B: Healing of esophageal anastomosis; Animal experiments. Ann Surg 150: 142-148, 1959.

30. Halaszynski TM, Juda R and Silverman DG: Optimizing postoperative outcomes with efficient preoperative assessment and management. Crit Care Med 32 (4 Suppl): S76-S86, 2004.

31. Forster AJ, Clark HD, Menard A, Dupuis N, Chernish R, Chandok N, Khan A, Letourneau M and van Walraven C: Effect of a nurse team coordinator on outcomes for hospitalized medicine patients. Am J Med 118: 1148-1153, 2005.

32. Berberat PO, Ingold H, Gulbinas A, Kleeff J, Müller MW, Gutt C, Weigand M, Friess H and Büchler MW: Fast track-different implications in pancreatic surgery. J Gastrointest Surg 11: 880-887, 2007.

33. White H, Sosnowski K, Tran K, Reeves A and Jones M: A randomised controlled comparison of early post-pyloric versus early gastric feeding to meet nutritional targets in ventilated intensive care patients. Crit Care 13: R187, 2009.

34. Balzano G, Zerbi A, Braga M, Rocchetti S, Beneduce AA and Di Carlo V: Fast-track recovery programme after pancreaticoduodenectomy reduces delayed gastric emptying. Br J Surg 95: 1387-1393, 2008

35. di Sebastiano P, Festa L, De Bonis A, Ciuffreda A, Valvano MR, Andriulli A and di Mola FF: A modified fast-track program for pancreatic surgery: A prospective single-center experience. Langenbecks Arch Surg 396: 345-351, 2011. 